\title{
Cocaine- and amphetamine-regulated transcript (CART) is associated with dopamine and is protective against ischemic stroke
}

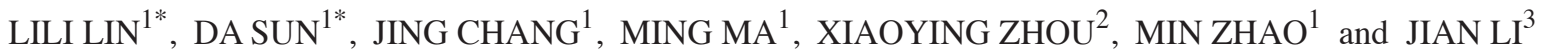 \\ Departments of ${ }^{1}$ Pharmacy and ${ }^{2}$ Nursing, Wuxi Higher Health Vocational Technology School, Wuxi, Jiangsu 214028; \\ ${ }^{3}$ Department of Cardiology, Wuxi People's Hospital Affiliated to Nanjing Medical University, Wuxi, Jiangsu 214023, P.R. China
}

Received November 19, 2015; Accepted May 2, 2018

DOI: $10.3892 / \mathrm{mmr} .2018 .9296$

\begin{abstract}
Cocaine and amphetamine-regulated transcript (CART) is a neuropeptide that can protect brains against ischemic injury. The aim of the present study was to investigate the effects of the CART within ischemic stroke and it possible mechanism. The expression levels of dopamine (DA) and CART in ischemic brain tissues of mice were measured following middle cerebral artery occlusion (MCAO). After receiving the treatment of $\mathrm{DA}$ and $\mathrm{CART}$, the infarct volume of brain was measured in mice with MCAO. In addition, the function and potential mechanism of CART in ischemic stroke were further investigated. DA and CART expression was significantly decreased in mice with MCAO compared with normal control mice. Treatment of mice with MCAO with exogenous CART significantly decreased the extent of brain injury compared with untreated mice with MCAO. Treatment with exogenous CART promoted the survival of ex vivo neurons following oxygen-glucose deprivation (OGD), while exogenous DA induced CART mRNA expression in a dose-dependent manner, which suggested an association between CART and DA. Apoptosis of ex vivo neurons was significantly increased following OGD, however treatment with exogenous CART significantly inhibited this effect. The potential mechanism of CART was determined to be associated with inflammatory cytokines and related apoptotic genes. CART therefore appears to be associated with DA in its effect on ischemic stroke and is protective against brain injury following ischemic stroke by reducing inflammation activation; it may provide a promising means to treat ischemic stroke patients.
\end{abstract}

Correspondence to: Dr Jian Li, Department of Cardiology, Wuxi People's Hospital Affiliated to Nanjing Medical University, 299 Qing Yang Road, Wuxi, Jiangsu 214023, P.R. China

E-mail: 1ijian0551@163.com

${ }^{*}$ Contributed equally

Key words: cocaine- and amphetamine-regulated transcript protein, middle cerebral artery occlusion, dopamine, ischemic stroke, inflammation

\section{Introduction}

Cocaine- and amphetamine-regulated transcript (CART) is a neuropeptide that is widely expressed in normal brain tissue and is involved in a variety of physiological processes (1-3). Previous studies have indicated that CART serves a neuroprotective role in rat models of middle cerebral artery occlusion (MCAO) and in cultured primary cortical neurons (4-6). CART treatment can promote the differentiation of neural progenitor cells and the migration of cells toward the ischemic cortex in rat models of MCAO (7).

Dopamine (DA) is crucial for most brain functions during brain development, and is important in the regulation of physiological processes, such as motor learning and motor control $(8,9)$. Reduced dopamine levels have been frequently recorded in patients with Parkinson's disease (PD) and ischemic stroke $(10,11)$. Studies using rat models suggested that a reduced dopamine level results from the leakage from the striatum into extracellular tissues during the acute phase of cerebral ischemia (12-14), whereas levodopa treatment can improve functional rehabilitation after stroke by increasing local dopamine levels (15). Meanwhile, dopamine treatment is beneficial for the rehabilitation in patients with stroke (16-18).

However, it is unknown whether the role of CART correlates with DA during the process of neuronal recovery or repair following neuronal injury. Furthermore, the molecular mechanism of CART in aiding neuronal recovery and repair following this injury remains elusive. In the present work, a potential association between CART and DA in ischemic stroke was investigated, as well as elucidation of the potential function and molecular mechanism of CART.

\section{Materials and methods}

Animals and ischemic models. A total of 30 Male C57BL/6J mice (weight, 15-18 g; age, 14 months) were obtained from the Animal Center of Peking University Health Science Center (Beijing, China). Prior to the start of experiments, all mice were provided with free access to standard laboratory chow and water at $24-28^{\circ} \mathrm{C}$ with $40 \%$ humidity and 12 -h light/dark cycle. The procedures were in accordance with the National Institutes of Health Guide for the Care and Use of Laboratory Animals (Bethesda, MA, USA) and were approved by the Animal Ethical and Welfare committee of Wuxi 
Higher Health Vocational Technology School. The models of MCAO were produced as previously described (19). Mice were anesthetized by the intraperitoneal injection of sodium pentobarbital $(40 \mathrm{mg} / \mathrm{kg})$. A nylon suture with heat-rounded tip was inserted into the external carotid artery to obstruct the opening of the middle cerebral artery. Following occlusion for $6 \mathrm{~h}$, the blood reperfusion was recovered. After 2 days, mice were treated with levodopa (1 ng per 1 gram body weight) or exogenous DA (0-100 mg/kg, n=10; cat. no. AAA1113614; Thermo Fisher Scientific, Inc., Waltham, MA, USA) or CART peptide $(2.5 \mathrm{mg} / \mathrm{kg}, \mathrm{n}=10$; cat. no. AAJ66304MCR; Thermo Fisher Scientific, Inc.) for 12 consecutive days. Then mice were sacrificed under deep halothane anesthesia, the brain tissues were quickly frozen in liquid nitrogen, sliced into $10 \mu \mathrm{m}$ thick sections and stained using 2,3,5-triphenyltetrazolium chloride for infarct measurement. The mice that underwent the same procedure without MCAO were considered as controls.

Enzyme-linked immunosorbent assay (ELISA). Following MCAO for $6 \mathrm{~h}$, the immunoreactivity of the DA in blood samples was detected using ELISA kit (cat. no. MBS725908; MyBioSource, Inc., San Diego, CA, USA), in accordance with the manufacturer's instructions. Briefly, blood samples were collected and centrifuged at $300 \mathrm{x} \mathrm{g}$ for $5 \mathrm{~min}$ at $4^{\circ} \mathrm{C}$. A total of $20 \mu \mathrm{l}$ plasma was added to $100 \mu \mathrm{l}$ assay buffer in each well of a 96 microwell plate and incubated overnight at $4^{\circ} \mathrm{C}$ with DA antibody (ab20066; Abcam, Cambridge, MA, USA) and without DA antibody (negative controls). Following washing with PBS with $0.25 \%$ Tween-20 (PBST), plates were incubated with horseradish peroxidase-conjugated streptavidin (N100; Thermo Fisher Scientific, Inc., Waltham, MA, USA) for $1 \mathrm{~h}$ and detected by tetramethylbenzidine (cat. no. 860336; Sigma-Aldrich; Merck KGaA, Darmstadt, Germany). Optical density (OD) values were determined using a Varioskan Flash Multimode reader (Thermo Fisher Scientific, Inc.) at $450 \mathrm{~nm}$, and test concentrations determined according to the protein standard curve.

Primary cortical neuron cultures. Primary cultures of cortical neurons were collected from two neonatal mice as described previously (19). The mice were purchased from the animal facility of the Peking University Health Science Center (Beijing, China), The procedures were approved by the Animal Ethical and Welfare committee of Wuxi Higher Health Vocational Technology School. In brief, cells were cultured with Dulbecco's modified Eagle's medium (DMEM; Invitrogen; Thermo Fisher Scientific, Inc.) supplemented with $12 \%$ fetal bovine serum (FBS; Hyclone; GE Healthcare Life Sciences, Logan, UT, USA) at $37^{\circ} \mathrm{C}$ under an atmosphere containing $5 \% \mathrm{CO}_{2}$. When cells reach $\sim 80 \%$ confluence, they were harvested and stored at $-80^{\circ} \mathrm{C}$ for further investigation.

Oxygen-glucose deprivation (OGD) and cell viability detection. To obtain the OGD conditions, primary mouse cortical neurons were cultured with DMEM without glucose under at $37^{\circ} \mathrm{C}$ in a $95 \% \mathrm{~N}_{2}$ with $5 \% \mathrm{CO}_{2}$ incubator. Following $6 \mathrm{~h}$ incubation, OGD was terminated and primary mouse cortical neurons were cultured with fresh DMEM supplemented with $12 \% \mathrm{FBS}$ at $37^{\circ} \mathrm{C}$ under $95 \% \mathrm{~N}_{2}$ with $5 \% \mathrm{CO}_{2}$. Following another $6 \mathrm{~h}$ of OGD incubation, cortical neurons were treated with different doses of exogenous CART and DA (0, 0.2, 2 and $20 \mathrm{mg}$ respectively), and cell viability was evaluated by MTT assay. Briefly, neurons in each group were treated with MTT $(0.5 \mathrm{mg} / \mathrm{ml}$, Sigma-Aldrich; Merck KGaA) for $4 \mathrm{~h}$ at $37^{\circ} \mathrm{C}$ and incubated with $100 \mu \mathrm{l}$ dimethyl sulfoxide for $10 \mathrm{~min}$. The absorbance was measured at $570 \mathrm{~nm}$.

Flow cytometry for cell apoptosis. Cortical neurons, OGD treated cortical neurons, CART treated cortical neurons, CART- and OGD-co-treated cortical neurons $\left(2 \times 10^{6}\right)$ were digested with $0.25 \%$ trypsin and washed twice with PBS. Cells were then collected and incubated with $100 \mu \mathrm{l}$ propidium iodide and $300 \mu \mathrm{l}$ Annexin V-fluorescein isothiocyanate staining solution (Sigma-Aldrich; Merck-Millipore) for $15 \mathrm{~min}$ in the dark. Cell apoptosis was examined using flow cytometry (FACSCalibur; BD Biosciences, Franklin Lakes, NJ, USA).

Reverse transcription-quantitative polymerase chain reaction $(R T-q P C R)$. All procedures were performed using the manufacturer's instructions. Total RNA was extracted using TRIzol reagent (Invitrogen; Thermo Fisher Scientific, Inc.). The concentration of total RNA was measured by the UV absorption method and reverse transcribed into cDNA by using PrimeScript RT reagent kit (Takara Biotechnology Co., Ltd., Dalian, China). qPCR was performed at least three times using an ABI 7500 instrument (Applied Biosystems; Thermo Fisher Scientific, Inc.). The thermal cycling conditions of qPCR were as follows: Pre-denaturing at $95^{\circ} \mathrm{C}$ for $30 \mathrm{sec}$, PCR reaction 40 cycles at $95^{\circ} \mathrm{C}$ for $5 \mathrm{sec}$ and at $60^{\circ} \mathrm{C}$ for $34 \mathrm{sec}$. The primer sequences were as follows: Caspase-1 forward, 5'-GACCGA GTGGTTCCCTCAAG-3' and reverse, 5'-GACGTGTACGAG TGGGTGTT-3'; caspase-3 forward, 5'-TGTGGCATTGAG ACAGAC-3' and reverse, 5'-CACTTGCCATACAAACTA-3'; nucleotide-binding oligomerization domain-containing protein (NOD)1 forward, 5'-TCAGCAATGAAAGGCGGG AT-3' and reverse, 5'-TCCGAATGTTGGTGACCAGG-3'; NOD2 forward, 5'-GTGTCAGCTCAGTCTCGCTT-3' and reverse, 5'-GTCCGCAGCTCTAAGGTGTT-3'; chemokine (C-C motif) ligand 2 (CCL2) forward, 5'-TAGCATCCACGT GCTGTCTC-3' and reverse, 5'-CAGCCGACTCATTGGGAT CA-3'; interleukin-1 $\beta$ (IL-1 $\beta$ ) forward, 5'-TGGGAAGCTTCA GCTGTCTG-3' and reverse, 5'-GTTGGGCTGGCATCTGGT AT-3'; tumor necrosis factor- $\alpha$ (TNF- $\alpha$ ) forward, 5'-TTCTCA TTCCTGCTCGTGG-3' and reverse, 5'-TTTGGTGGTTCG CCTCCT-3'. $\beta$-actin forward, 5'-CCTCGCCTTTGCCGA TCC-3' and reverse, 5'-GGATCTTCATGAGGTAGTCAG TC-3'. Housekeeping gene $\beta$-actin was used as an internal reference to normalize the results. The $2^{-\Delta \Delta \mathrm{Cq}}$ method was performed to calculate the relative expression (20).

Western blot analysis. Total protein was extracted using a lysis buffer (cat. no. PI87787; Thermo Fisher Scientific, Inc.) and quantified by the bicinchoninic acid method. Cell lysates (30 $\mu \mathrm{g})$ were separated using 10\% SDS-PAGE and transferred to polyvinylidene difluoride membranes. The membranes were blocked using blocking buffer (PBS, 0.1\% Tween-20 and $5 \%$ nonfat dry milk) for $2 \mathrm{~h}$ at room temperature. Then, the membranes were incubated with primary antibodies against caspase-1 (cat. no. sc-398715; dilution, 1:500), caspase-3 (cat. no. sc-7148; dilution, 1:500), Bcl-2 (cat. no. sc-7382; 


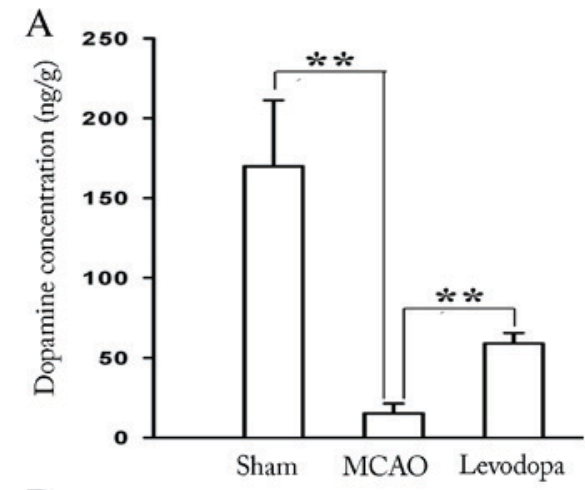

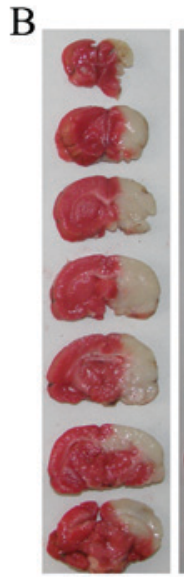

$\mathrm{DA} / \mathrm{mg} 0$

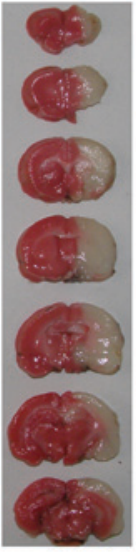

0.2

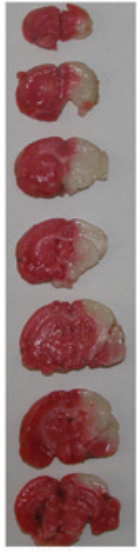

2

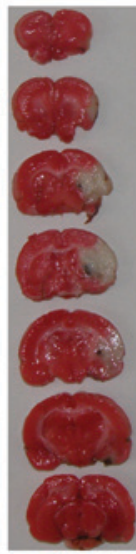

20

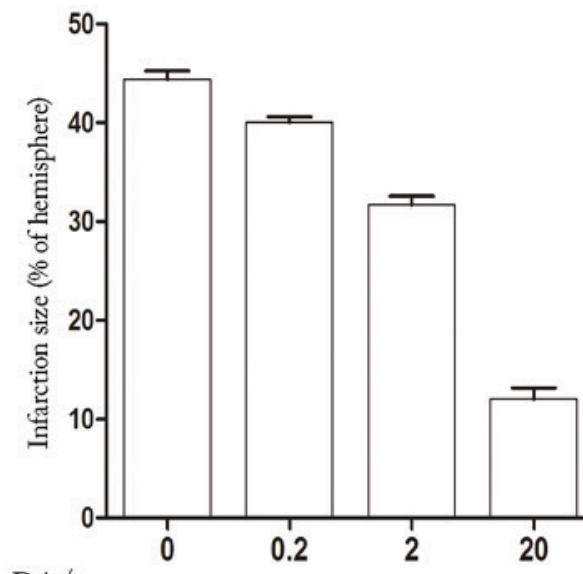

$\mathrm{DA} / \mathrm{mg}$

Figure 1. Dopamine reduces brain injury in mice following MCAO. (A) The level of endogenous DA in serum following $6 \mathrm{~h}$ MCAO was detected by enzyme-linked immunosorbent assay. ${ }^{* *} \mathrm{P}<0.01$, with comparisons indicated by brackets. (B) The infarct volume of MCAO mice was analyzed by $2,3,5$-triphenyltetrazolium chloride staining following MCAO and treatment with exogenous DA, with living tissue stained red, and the area of infarct in white. MCAO, middle cerebral artery occlusion; DA, levels of dopamine.

dilution, 1:500), Bax (cat. no. sc-6236; dilution, 1:500), IL-1 $\beta$ (cat. no. sc-12742; dilution, 1:500), TNF- $\alpha$ (cat. no. sc-4890, dilution, 1:500) and GAPDH (cat. no. sc-20356; dilution, $1: 1,000)$, at $4^{\circ} \mathrm{C}$ overnight. All primary antibodies were purchased from Santa Cruz Biotechnology, Inc. (Dallas, TX, USA). All membranes were washed with PBST and incubated with second antibody at room temperature for $1 \mathrm{~h}$, including Goat anti-Rat (cat. no. ab7010; 1:500; Abcam), Donkey anti-Rabbit (cat. no. ab98489; 1:600; Abcam), Goat Anti-Mouse (cat. no. ab7067; 1:600; Abcam). The signal was detected by enhanced chemiluminescence (Pierce; Thermo Fisher Scientific, Inc.).

Statistical analysis. Statistical analysis was performed using SPSS software (version, 19.0; IBM SPSS, Armonk, NY, USA). All data are presented as the mean \pm standard error of the mean. Differences between two groups were tested by the unpaired Student's t-test and difference among three or four groups were assessed using one-way analysis of variance. $\mathrm{P}<0.05$ was considered to indicate a statistically significant difference.

\section{Results}

Dopamine reduces brain injury in mice following MCAO. To investigate the relationship between DA and brain injury, a mouse model of MCAO was utilized. The results revealed that the level of DA following MCAO was significantly decreased compared with the control (Sham) group ( $\mathrm{P}=0.023$; Fig. 1A). It was noticeable that levodopa treatment following MCAO could reverse the change with a significant increase in $\mathrm{DA}(\mathrm{P}=0.016$; Fig. $1 \mathrm{~A})$. To investigate whether DA could reduce brain injury following MCAO, mice were treated with 0, 0.2, 2 and $20 \mathrm{mg}$ of DA for 12 days after MCAO. As presented in Fig. 1B, DA evidently reduced the infarct volume of MCAO mice in a dose-dependent manner, suggesting that DA could reduce brain injury.

$C A R T$ reduces brain injury in mice following MCAO. It has previously been reported that CART is neuroprotective in rat models of MCAO (4-6). To confirm the observation, endogenous CART expression was measured in mice following MCAO. As expected, CART expression was significantly reduced following MCAO induction compared control mice $(\mathrm{P}=0.010$; Fig. 2A). MCAO mice were then treated with $20 \mathrm{mg} / \mathrm{kg}$ exogenous CART for 12 days following $\mathrm{MCAO}$, which resulted in significantly reduced infarct volume compared with the MCAO untreated group ( $\mathrm{P}=0.018$; Fig. $2 \mathrm{~B}$ ). These results were consistent with the observation caused by DA treatment, suggesting that CART may be associated with DA may be cooperative in protecting against brain injury following ischemic stroke.

To investigate whether the role of CART in protecting the brain injury was associated with cell inflammation, the levels of inflammatory factors including NOD1, NOD2, CCL2 and IL-1 $\beta$ were detected, along with the expression of relevant 
A

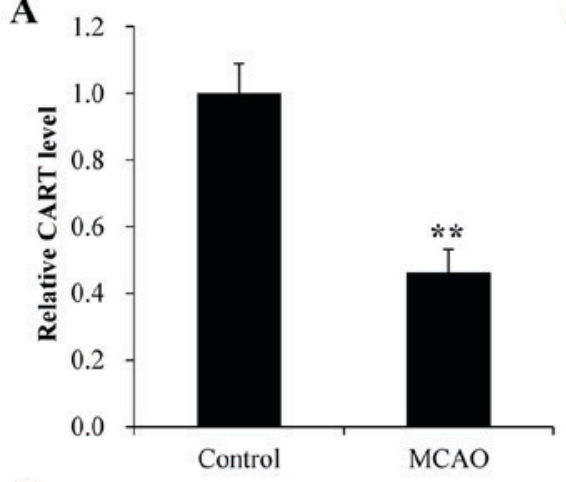

C

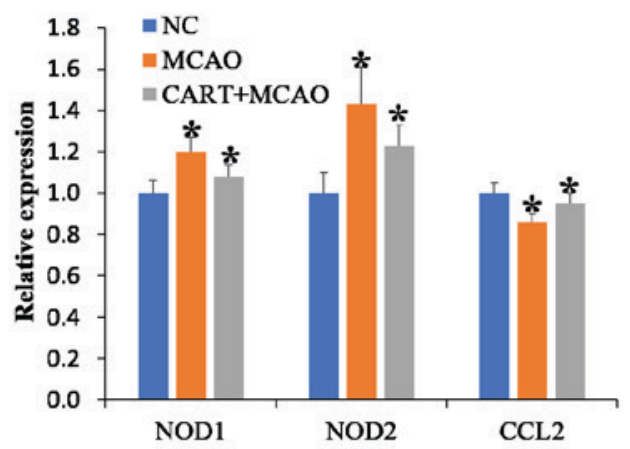

B

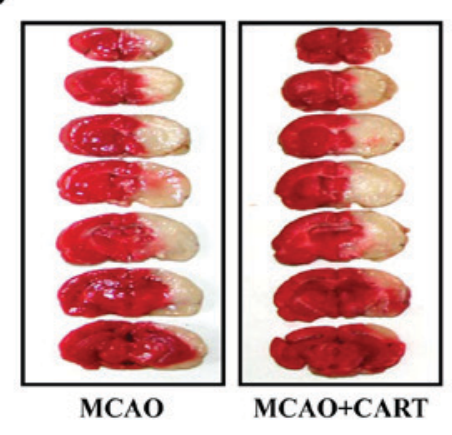

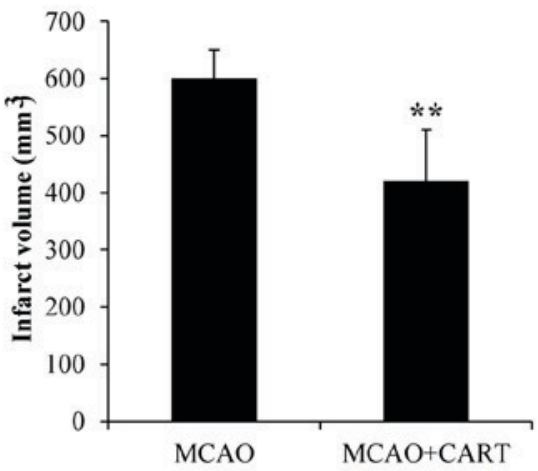

D
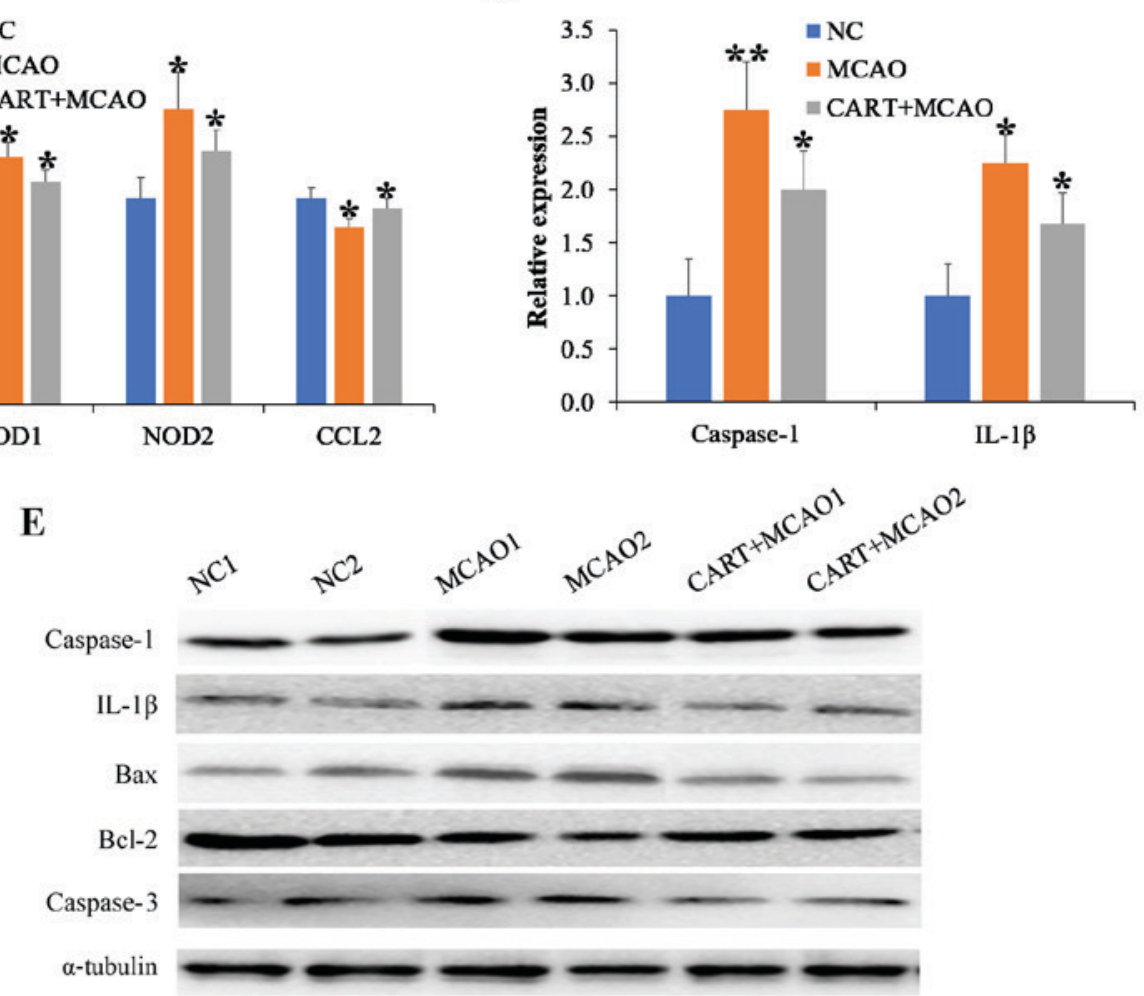

Figure 2. CART reduces brain injury in mice following MCAO. (A) Endogenous CART expression was detected by RT-qPCR. ${ }^{* *} \mathrm{P}<0.01$ vs. control. (B) The infarct volume of MCAO mice was analyzed by TTC staining following treatment with exogenous CART, with living tissue stained red, and the area of infarct in white. ${ }^{* *} \mathrm{P}<0.01$ vs. MCAO. (C) The levels of inflammatory mediators were measured by RT-qPCR following MCAO. ${ }^{*} \mathrm{P}<0.05$ vs. control. (D) The expression of inflammatory mediators was examined by RT-qPCR following treatment with exogenous CART in animals with $\mathrm{MCAO}$. * $\mathrm{P}<0.05$ and ${ }^{* *} \mathrm{P}<0.01$ vs. control. (E) The expression of inflammatory mediators was examined by western blot following treatment with exogenous CART in animals with MCAO. CART, cocaine- and amphetamine-regulated transcript; MCAO, middle cerebral artery occlusion; RT-qPCR, reverse transcription-quantitative polymerase chain reaction; NOD, nucleotide-binding oligomerization domain-containing protein; CCL2, chemokine (C-C motif) ligand 2; IL-1 $\beta$, interleukin-1 $\beta$; Bcl-2, B-cell lymphoma 2 apoptosis regulator; Bax, Bcl-2 associated protein $\mathrm{X}$ apoptosis regulator.

apoptotic factors, including caspase-1, caspase-3, Bcl-2 and Bax. As indicated in Fig. 2C, the mRNA expression levels of NOD1, NOD2 and CCL2 were elevated following MCAO, as measured by RT-qPCR. However, CART treatment decreased the mRNA expression levels of NOD1, NOD2 and CCL2, as well as inhibiting the expression of caspase- 1 and IL- $1 \beta$ when compared with controls (Fig. 2D). In addition, western blot analysis indicated that compared with controls, protein expression levels of caspase-1, IL-1 $\beta$ and caspase-3 were elevated in brain tissues following MCAO, and that CART treatment reversed the effect (Fig. 2E). increased survival and reduced apoptosis in OGD neurons ex vivo. The viability of ex vivo neurons following OGD and treatment with exogenous DA was evaluated by MTT assay. As demonstrated in Fig. 3A, the survival rate of neurons was significantly decreased following OGD when compared with normal controls $(\mathrm{P}=0.021)$. No significant increase in viability of OGD neurons was observed following treatment with exogenous DA, compared with untreated OGD cells (Fig. 3A). However, increasing exogenous DA concentrations did result in higher levels of CART mRNA expression (Fig. 3B). Compared with treatment with $1 \mathrm{ng} / \mathrm{ml}$ of exogenous DA, higher concentrations ( 3 and $10 \mathrm{ng} / \mathrm{ml}$ ) resulted in higher levels of CART mRNA expression, although the levels of CART mRNA expression in neurons remained lower than those without OGD even with $10 \mathrm{ng} / \mathrm{ml} \mathrm{DA}(\mathrm{P}=0.031$; Fig. $3 \mathrm{~B})$. 


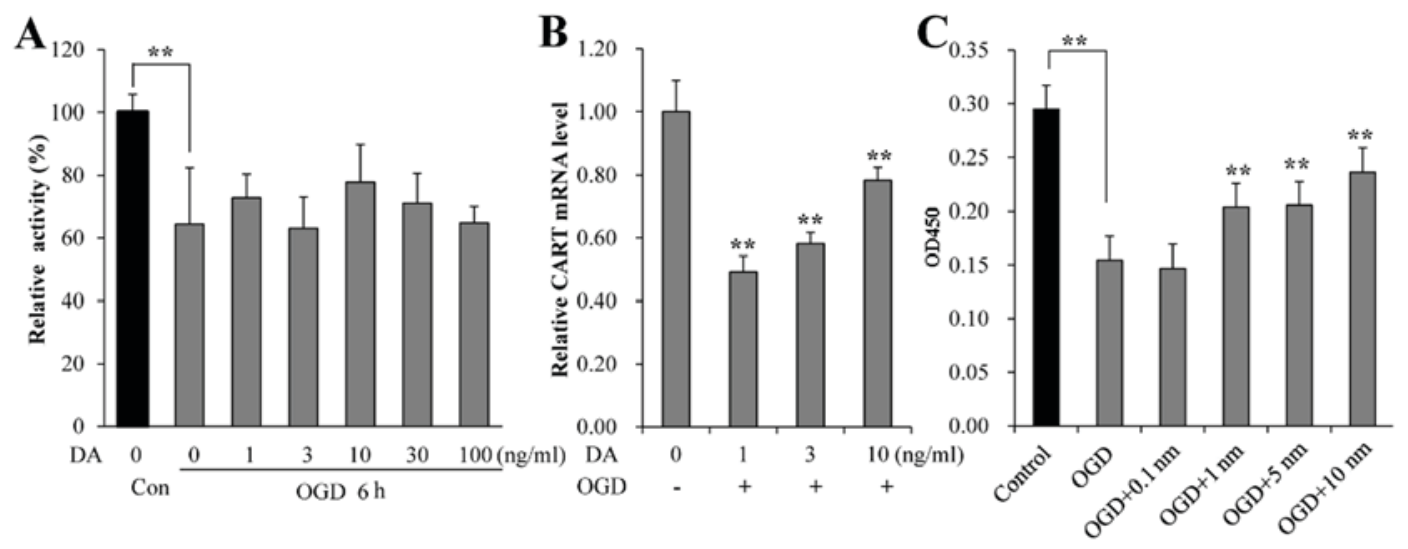

Figure 3. CART is associated with DA and promotes the survival of ex vivo OGD neurons. (A) The viability of neurons was evaluated by MTT assay in OGD neurons following treatment with exogenous DA. (B) Endogenous CART mRNA expression levels were detected in OGD neurons by reverse transcription-quantitative polymerase chain reaction following treatment with exogenous DA. (C) The viability of OGD neurons was evaluated by MTT assay following treatment with exogenous CART. ${ }^{* *} \mathrm{P}<0.01$ vs. normal untreated control or OGD group. CART, cocaine- and amphetamine-regulated transcript; DA, dopamine; OGD, oxygen-glucose deprivation; Con, control.

A
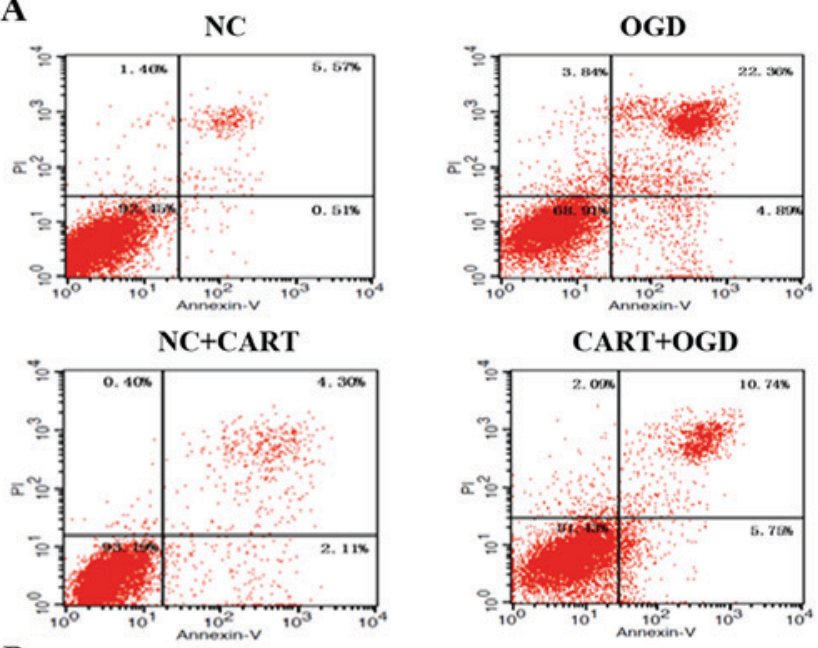

B

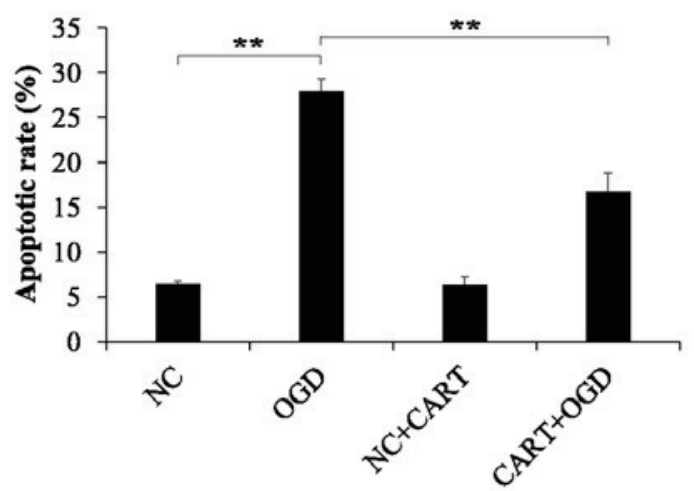

Figure 4. Cell apoptosis evaluated by flow cytometry. (A) The apoptosis rate of neurons was significantly increased following OGD $(27.98 \% \pm 1.38)$ when compared with the NC group $(6.29 \% \pm 0.94, \mathrm{P}<0.05)$; CART treatment significantly decreased the cell apoptosis in OGD neurons $(16.76 \% \pm 2.04)$ when compared with the $\mathrm{NC}+\mathrm{CART}$ group $(6.48 \% \pm 0.26, \mathrm{P}<0.05)$. (B) The quantification of apoptotic rate of $\mathrm{NC}$, OGD, NC+CART and OGD+CART group respectively. ${ }^{* *} \mathrm{P}<0.01$. OGD, oxygen-glucose deprivation; CART, cocaine- and amphetamine-regulated transcript; PI, propidium iodide.

When OGD neurons were treated with 1,5 and $10 \mathrm{ng} / \mathrm{ml}$ of exogenous CART, cell viability was significantly elevated, in a dose-dependent manner, compared with OGD neurons

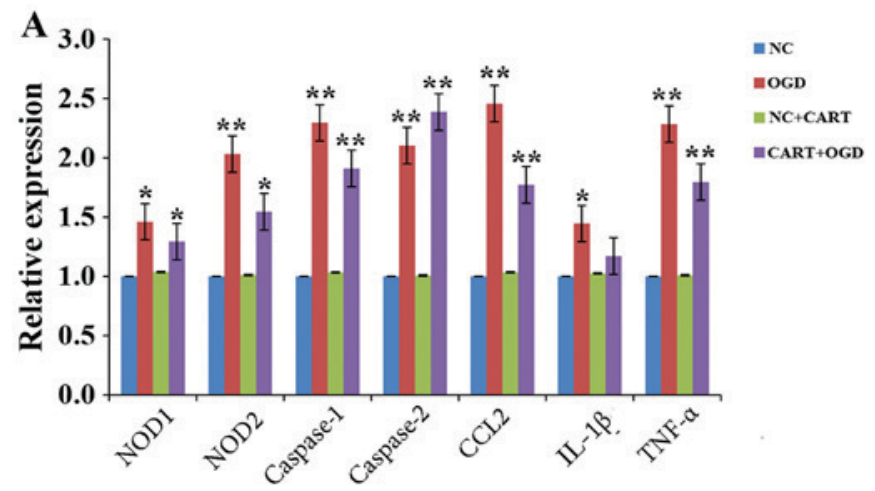

B

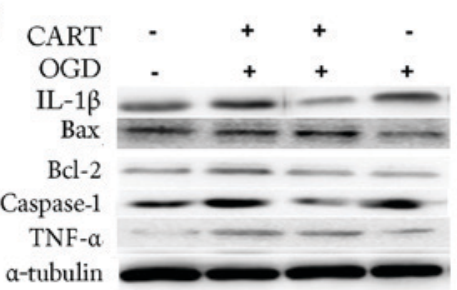

Figure 5. CART inhibits the expression of inflammatory cytokines and apoptotic proteins in ex vivo OGD neurons. (A) mRNA expression of inflammatory cytokines and apoptotic proteins in neurons was detected by reverse transcription-quantitative polymerase chain reaction. (B) The expression of inflammatory cytokines and apoptotic proteins in neurons was detected by western blot analysis. ${ }^{*} \mathrm{P}<0.05 ;{ }^{* *} \mathrm{P}<0.01$ vs. normal untreated control. NC, negative control; OGD, oxygen-glucose deprivation; CART, cocaine- and amphetamine-regulated transcript; NOD, nucleotide-binding oligomerization domain-containing protein; CCL2, chemokine (C-C motif) ligand 2; IL-1 $\beta$, interleukin- $1 \beta$; TNF- $\alpha$, tumor necrosis factor- $\alpha$; Bcl-2, B-cell lymphoma 2 apoptosis regulator; $\mathrm{Bax}, \mathrm{Bcl}-2$ associated protein $\mathrm{X}$ apoptosis regulator.

without CART treatment ( $\mathrm{P}=0.027$; Fig. 3C). Thus, these data indicated that CART was associated with DA and promoted the survival of neurons. In addition, cell apoptosis was measured by flow cytometry. As indicated in Fig. 4, the apoptosis rate of neurons was significantly increased following OGD compared with the controls $(\mathrm{P}=0.001)$. However, cell apoptosis was significantly reduced in OGD neurons following treatment with exogenous CART when compared with OGD treated neurons $(\mathrm{P}=0.012$; Fig. 4B). 
CART inhibits the expression of inflammatory cytokines and apoptotic proteins in ex vivo OGD neurons. To investigate the potential mechanism of CART protection against OGD, the mRNA and protein expression levels of inflammatory cytokines and apoptotic proteins were evaluated in neurons by RT-qPCR and western blot analysis, respectively. The mRNA expression levels of NOD1, NOD2, CCL2, caspase-1, caspase-3, IL-1 $\beta$ and TNF- $\alpha$ were significantly elevated in OGD neurons compared with control, while their levels were decreased in OGD neurons following treatment with exogenous CART compared with untreated OGD neurons (Fig. 5A). In addition, the protein expression levels of caspase-1, IL-1 $\beta, \mathrm{Bcl}-2$ and TNF- $\alpha$ were also elevated following OGD compared with normal neurons, but the expression of Bax was decreased (Fig. 5B). However, CART treatment reversed the effect (Fig. 5B).

\section{Discussion}

CART is prevalent within the hypothalamus, midbrain and thalamus, but is rarely observed in the hindbrain, hippocampus, ventral striatum and cerebral cortex (1). CART is involved in various physiological functions and serves key roles in nervous system conditions, such as brain injury, epilepsy and dementia $(21,22)$. DA is crucial for most brain functions during its development and is involved within nervous system diseases such as PD and ischemic stroke (10-12). However, whether CART cooperates with DA to play a cooperative role in brain injury remains elusive.

In order to investigate the relationship between CART and DA, their expression in a MCAO brain injury model was examined. The level of DA was markedly decreased following MCAO when compared with the control groups, while levodopa treatment reversed the change with a significant increase of DA. This suggests that DA is involved in the progression of brain injury. Meanwhile, it was identified that CART expression was reduced in brain tissues following $\mathrm{MCAO}$, but that treatment with exogenous CART following MCAO significantly decreased the extent of brain injury compared. In order to investigate whether the role of CART in protecting against brain injury was associated with cell inflammation, the levels of inflammatory factors including NOD1, NOD2, CCL2 and IL-1 $\beta$ were measured in brain tissues, as well as the expression of apoptotic factors, caspase-1, caspase-3, Bcl-2 and Bax. Inflammatory factors were found to be activated and cell apoptosis increased in mice with MCAO, while treatment with exogenous CART reversed the effect. These results indicated that CART may be protective against brain injury, through regulation of inflammatory factors. Also, Chang et al (23) reported that CART treatment blocks the increase of cytokine expression induced by brain injury in experimental stroke. However, Xu et al (19) reported that CART played a neurodegenerative role in estrogen-mediated neuroprotection by activating the ERK/MAPK pathway.

Previous studies have reported that the mitochondrial respiratory chain was activated following ischemic stroke, resulting in increased lipid peroxidation and the injury of mitochondrial DNA by enhanced production of intracellular reactive oxygen species $(24,25)$. Therefore, the oxidative stress injury following ischemia would be reduced if the overproduction of reactive oxygen species was inhibited. In the present study, the survival rate of neurons following OGD was significantly reduced compared with normal neurons. CART treatment promoted the survival of neurons following OGD, while exogenous DA induced CART mRNA expression in a dose-dependent manner, which suggested an association between CART and DA. In addition, the apoptosis rate was markedly increased in OGD neurons compared with normal neurons, but this effect was significantly inhibited by treatment with exogenous CART. The potential mechanism of the effect of CART was linked to inflammatory cytokines, such as NOD1, NOD2, CCL2, IL-1 $\beta$ and TNF- $\alpha$, and related apoptotic proteins such as caspase- 1 . These data further validate that CART may be protective during ischemic stroke by regulation of inflammatory cytokines and apoptotic proteins. It may provide a promising method to treat ischemic stroke patients.

\section{Acknowledgements}

Not applicable.

\section{Funding}

The present study was supported by 2013 General Programs of Health Bureau of Wuxi (grant no. ML201315).

\section{Availability of data and materials}

The datasets used and/or analyzed during the current study are available from the corresponding author on reasonable request.

\section{Authors' contributions}

LL, DS and JL designed the present study. JL gave final approval of the version to be published. JC performed experiments and analysis the data, and wrote and revised the manuscript. MM and XZ made substantial contributions to acquisition of data, or analysis and interpretation of data. LL, DS and MZ performed experiments and collected data. All authors have read and approved the manuscript.

\section{Ethics approval and consent to participate}

The procedures were in accordance with the National Institutes of Health Guide for the Care and Use of Laboratory Animals (Bethesda, MA, USA) and were approved by the Animal Ethical and Welfare committee of Wuxi Higher Health Vocational Technology School.

\section{Patient consent for publication}

Not applicable.

\section{Competing interests}

The authors declare that they have no competing interests.

\section{References}

1. Douglass J, McKinzie AA and Couceyro P: PCR differential display identifies a rat brain mRNA that is transcriptionally regulated by cocaine and amphetamine. J Neurosci 15: 2471-2481, 1995. 
2. Wierup N, Kuhar M, Nilsson BO, Mulder H, Ekblad E and Sundler F: Cocaine- and amphetamine-regulated transcript (CART) is expressed in several islet cell types during rat development. J Histochem Cytochem 52: 169-177, 2004

3. Rogge G, Jones D, Hubert GW, Lin Y and Kuhar MJ: CART peptides: Regulators of body weight, reward and other functions. Nat Rev Neurosci 9: 747-758, 2008.

4. $\mathrm{Wu} \mathrm{B}, \mathrm{Hu} \mathrm{S}$, Yang M, Pan $\mathrm{H}$ and Zhu S: CART peptide promotes the survival of hippocampal neurons by upregulating brain-derived neurotrophic factor. Biochem Biophys Res Commun 347: 656-661, 2006.

5. Mao P, Ardeshiri A, Jacks R, Yang S, Hurn PD and Alkayed NJ: Mitochondrial mechanism of neuroprotection by CART. Eur J Neurosci 26: 624-632, 2007.

6. Jia J, Chen X, Zhu W, Luo Y, Hua Z and Xu Y: CART protects brain from damage through ERK activation in ischemic stroke. Neuropeptides 42: 653-661, 2008.

7. Luo Y, Shen H, Liu HS, Yu SJ, Reiner DJ, Harvey BK, Hoffer BJ, Yang Y and Wang Y: CART peptide induces neuroregeneration in stroke rats. J Cereb Blood Flow Metab 33: 300-310, 2013.

8. Hosp JA, Pekanovic A, Rioult-Pedotti MS and Luft A: Dopaminergic projections from midbrain to primary motor cortex mediate motor skill learning. J Neurosci 31: 2481-2487, 2011.

9. Kawashima S, Ueki Y, Kato T, Matsukawa N, Mima T, Hallett M, Ito $\mathrm{K}$ and Ojika $\mathrm{K}$ : Changes in striatal dopamine release associated with human motor-skill acquisition. PLoS One 7 : e31728, 2012.

10. Calne DB and Sandler M: L-Dopa and parkinsonism. Nature 226 21-24, 1970.

11. Bhakta BB, Hartley S, Holloway I, Couzens JA, Ford GA, Meads D, Sackley CM, Walker MF, Ruddock SP and Farrin AJ: The DARS (Dopamine Augmented Rehabilitation in Stroke) trial: protocol for a randomised controlled trial of Co-careldopa treatment in addition to routine NHS occupational and physical therapy after stroke. Trials 15: 316, 2014.

12. Brannan T, Weinberger J, Knott P, Taff I, Kaufmann H Togasaki D, Nieves-Rosa J and Maker H: Direct evidence of acute, massive striatal dopamine release in gerbils with unilateral strokes. Stroke 18: 108-110, 1987.

13. Shin SS, Bray ER, Zhang CQ and Dixon CE: Traumatic brain injury reduces striatal tyrosine hydroxylase activity and potassium-evoked dopamine release in rats. Brain Res 1369: 208-215, 2011

14. Krysiak R, Kedzia A and Okopień B: The effect of oxcarbamazepine on the clinical effectiveness of dopamine agonists in the treatment of prolactinoma. Wiad Lek 64: 279-282, 2011.
15. Ruscher K, Kuric E and Wieloch T: Levodopa treatment improves functional recovery after experimental stroke. Stroke 43: 507-513, 2012.

16. PD Med Collaborative Group, Gray R, Ives N, Rick C, Patel S, Gray A, Jenkinson C, McIntosh E, Wheatley K, Williams A and Clarke CE: Long-term effectiveness of dopamine agonists and monoamine oxidase B inhibitors compared with levodopa as initial treatment for Parkinson's disease (PD MED): A large, open-label, pragmatic randomised trial. Lancet 384: 1196-1205, 2014.

17. Sami MB and Faruqui R: The effectiveness of dopamine agonists for treatment of neuropsychiatric symptoms post brain injury and stroke. Acta Neuropsychiatr 27: 317-326, 2015.

18. Zhao H, Cheng L, Liu Y, Zhang W, Maharjan S, Cui Z, Wang X, Tang D and Nie L: Mechanisms of anti-inflammatory property of conserved dopamine neurotrophic factor: Inhibition of JNK signaling in lipopolysaccharide-induced microglia. J Mol Neurosci 52: 186-192, 2014.

19. Xu Y, Zhang W, Klaus J, Young J, Koerner I, Sheldahl LC, Hurn PD, Martínez-Murillo F and Alkayed NJ: Role of cocaineand amphetamine-regulated transcript in estradiol-mediated neuroprotection. Proc Natl Acad Sci USA 103: 14489-14494, 2006.

20. Livak KJ and Schmittgen TD: Analysis of relative gene expression data using real-time quantitative PCR and the 2(-Delta Delta C(T)) method. Methods 25: 402-408, 2001.

21. Qing K and Chen Y: Central CART gene delivery by recombinant AAV vector attenuates body weight gain in diet-induced-obese rats. Regul Pept 140: 21-26, 2007.

22. Zhang $M$, Han $L$ and $\mathrm{Xu}$ Y: Roles of cocaine- and amphetamine-regulated transcript in the central nervous system. Clin Exp Pharmacol Physiol 39: 586-592, 2012.

23. Chang L, Chen Y, Li J, Liu Z, Wang Z, Chen J, Cao W and Xu Y: Cocaine- and amphetamine-regulated transcript modulates peripheral immunity and protects against brain injury in experimental stroke. Brain Behav Immun 25: 260-269, 2011.

24. Szeto HH: Mitochondria-targeted peptide antioxidants: Novel neuroprotective agents. AAPS J 8: E521-E531, 2006.

25. Turrens JF: Mitochondrial formation of reactive oxygen species. J Physiol 552: 335-344, 2003

This work is licensed under a Creative Commons Attribution-NonCommercial-NoDerivatives 4.0 International (CC BY-NC-ND 4.0) License. 